\title{
Human vulnerability to tornadoes in the United States is highest in
}

\author{
urbanized areas of the Mid South
}

James B. Elsner* and Tyler Fricker

Florida State University, Tallahassee, Florida

${ }_{5}^{*}$ Corresponding author address: James B. Elsner, Department of Geography, Florida State Univer-

6 sity, 113 Collegiate Loop, Tallahassee, FL 32301.

7 E-mail: jelsner@fsu.edu 


\begin{abstract}
8 Risk factors for tornado casualties are well known. Less understood is how 9 and to what degree these factors, after controlling for strength and the number 10 of people affected, vary over space and time. Here we fit models to casualty 11 counts from all casualty-producing tornadoes during the period 1995-2016 in 12 order to quantify the interactions between population and energy on casualty ${ }_{13}$ (deaths plus injuries) rates. Results show that the more populated areas of the ${ }_{14}$ Mid South are substantially and significantly more vulnerable to casualties 15 than elsewhere in the country. In this region casualty rates are significantly ${ }_{16}$ higher on the weekend. Night and day casualty rates are similar regardless 17 of where the tornadoes occur. States with a high percentage of older people ${ }_{18}(65+)$ tend to have greater vulnerability perhaps related to less agility and 19 fewer communication options.
\end{abstract}




\section{Introduction}

Nearly one fifth of all natural-hazards fatalities in the United States are the direct result of tornadoes (National Oceanic and Atmospheric Administration 2015). A tornado that hits a city is capable of inflicting hundreds or thousands of casualties. Data from the Storm Prediction Center (SPC) of the National Oceanic and Atmospheric Administration (NOAA) show that the 27 April 2011 Sawyerville-Eoline, Alabama tornado produced 1564 casualties with 64 of them resulting in death. Less than a month later the 22 May 2011 Joplin, MO tornado produced 1308 casualties with 158 of them resulting in death. More recently, the 26 December 2015 Garland-Rowlett, Texas tornado resulted in 10 deaths and 468 injuries.

Casualties occur when a tornado strikes where people live or work. Extreme wind speeds, relatively short warning lead times, and the quality of the built environments increase the potential for many casualties (Greenough et al. 2001). Risk factors for a casualty include sheltering in mobile homes, being an older adult, and accessibility to a safe room in a basement or in a reinforced structure (CDC 2012). In fact, early warnings and strong shelters are the most effective way to reduce death and injury (Bohonos and Hogan 1999). Moreover, the potential for a tornado disaster is not uniform across the country (Ashley and Strader 2016). Southern states are particularly vulnerable to casualties because of the relative abundance of mobile homes and the relative frequency of reduced visibility conditions (trees, hills, and heavy rain).

Statistically, given a tornado that produces at least one casualty, the casualty rate (how many people get injured or killed) depends on the number of people in harm's way and on the power of the winds inside the vortex. For an average number of people affected, casualties increase by $33 \%$ $( \pm 3 \%)$ with a doubling of the tornado energy and for an average amount of energy dissipated, casualties increase by $21 \%( \pm 3 \%)$ with a doubling of the number of people affected (Fricker 
et al. 2017). Thus as a percentage change, on average, energy is more important of the two in determining the casualty rate. But this finding might only be part of the story as the energy-casualty relationship may vary by population density. Indeed it is has been noted that rural communities are less vulnerable to casualties perhaps due to the unique nature of their social networks and culture (Donner 2007).

Donner (2007) argues that the types of relationships rural communities create, as well as the awareness people in such regions hold of their habitats, might help to protect otherwise vulnerable populations. He argues that perhaps strong social bonds expand the scope and availability of potential sources of weather information, access to shelters, and other resources that help with protective action. He speculates that urban areas are more vulnerable to casualties because of the rare occurrence of tornadoes in urban communities leads to lack of preparedness among residents, along with skepticism about the risks. Further, the presence of tall buildings and other objects may make it difficult to visually confirm the presence of tornadoes in urban communities. Without an environmental cue, warning responses tend to be lower (Mileti and O'Brien 1992).

The goal of this study is to better understand the relationship between tornado energy and casualties as modulated by population. Beyond the direct effects of population and energy on casualties as described in Fricker et al. (2017) it is important to understand possible interactions between these factors. Estimating interactions should help determine when and where communities are particularly vulnerable to casualties. For instance, it has been shown that casualty rates are lowest on weekdays when information flows more freely and when there are more robust sheltering-inplace opportunities at school and at work (Zahran et al. 2013).

The present research is grounded in the human ecology of tornado hazards (Boruff et al. 2003). The working hypothesis is that the change in casualties with energy is higher in tornadoes affecting more urbanized areas than more rural areas. The hypothesis arises from previous work suggesting 
greater vulnerability in cities relative to rural areas (Donner 2007). We define this differential as the rural-urban human vulnerability gradient. We test the hypothesis with a statistical model that includes population density within the tornado path and an estimate of the tornado's total energy dissipation. The objective is to establish statistical estimates of casualty rates as a function of energy across a range of population densities and to examine how these conditional rates might vary across time and space.

The statistical approach taken here is similar to that of recent work in examining factors related to tornado casualties (Lim et al. 2017; Zahran et al. 2013; Simmons and Sutter 2008; Donner 2007). However it differs in a couple of key ways. First, we use energy rather than path area, EF rating, or total damage as the indicator of tornado strength. Correlation among these variables is high but energy has a better physical justification as it is the power of the wind that is proximal to the cause of casualties. More importantly, from a statistical perspective, energy is a continuous variable. Second, we exclude tornadoes without casualties focusing instead on the number of casualties given at least one casualty. This makes the modeling simpler and interpretation of results more straightforward since, for a many of reasons, most tornadoes do not result in casualties. The question of whether or not a casualty occurs given a tornado is interesting and has been addressed elsewhere (e.g., Ashley et al. (2008)), but this question is beyond the scope of the present work. With these differences we aim to better statistically explain casualties (higher $R^{2}$ values) compared to what has been achieved in the past. Third, the study focuses on the interaction between the environmental factor (energy) and the demographic factor (population density) in explaining the rate of casualties. Indeed, the focus on the interaction between the environmental and demographic factors is unique among studies of this type and it provides a new lens with which to view factors that influence the rate of injuries and death from tornadoes. 
In brief, this study finds that the interaction between population and energy is substantial and statistically significant only in the Mid South including the states of Arkansas, Tennessee, and Missouri. Energy elasticity of casualties is lowest in rural areas and remains low with increasing population with the exception of the Mid South where elasticity in populated areas is significantly higher. The paper continues in Section 2 with a description of the data and the variables used in the analysis and modeling. The casualty model and results are presented in Section 3. The results include an investigation into the variability of the model's interaction term. A discussion of the findings is given in Section 4 followed by a list of conclusions in Section 5. All analysis and modeling are performed using the open-source $\mathrm{R}$ language for statistical computing (R Core Team 2016) with freely-available data. The $\mathrm{R}$ code and links to the data for this study are available at https://rpubs.com/jelsner/TornadoCasualtyRisk.

\section{Data and Variables}

\section{a. Tornado casualties}

Our interest in this work centers on the count of injuries and fatalities in the Storm Prediction Center's tornado database. The database is compiled from the National Weather Service's (NWS) Storm Data, and includes all known tornadoes dating back to 1950. A tornado casualty is defined as a fatality or injury directly attributable to a tornado, or impact by airborne, falling, or moving debris. A direct fatality would be a driver killed when a motor vehicle is tossed over. A direct injury requires treatment by a first-responder or treatment at a medical facility. A direct injury would be an person treated for a laceration caused by flying debris. Indirect casualties are not considered. Along with the per-tornado count of deaths and injuries each report includes the straight-line track, start location, damage path dimensions of length and maximum width, and the 
maximum Enhanced Fujita (EF) rating (damage rating on an ordered scale of categories from zero to five). Reports in the database are compiled by the NWS offices and reviewed by the National Climate Data Center (Verbout et al. 2006). We only consider tornadoes occurring within the conterminous United States.

During the 22-year period 1995-2016 there are 26,863 tornadoes recorded in the conterminous United States. Of these, 2,208 are linked to 25,968 casualties. Only 6.7 percent of all casualties lead to death. Most casualty-producing tornadoes result in only a few casualties, while relatively few casualty-producing tornadoes result in many casualties. The Tuscaloosa-Birmingham, Alabama tornado of 27 April 2011 and the Joplin, Missouri tornado of 22 May 2011 top the list of the most casualties in the period. The Tuscaloosa-Birmingham tornado was one of 362 tornadoes occurring between 25 and 28 April in the largest outbreak in recorded United States history. The Joplin tornado is the deadliest in the modern recorded-keeping era (since 1950).

On average a casualty-producing EF0 tornado results in two casualties (Table 1), a casualtyproducing EF1 tornado results in 3.1 casualties, and a casualty-producing EF2 tornado results in 6.5 casualties. Big increases in the expected number of casualties occur for the highest rated tornadoes. On average a casualty-producing EF3 tornado results in 20 casualties, a casualtyproducing EF4 tornado results in 62 casualties, and a casualty-producing EF5 tornado results in 236 casualties.

Tornado casualties during the period 1995-2016 are most common across the southeastern quarter of the country (Fig. 1). Larger events (more casualties) are associated with worse damage (higher EF rating). The number of casualty-producing tornadoes peaks in the EF1 and EF2 rating categories but the greatest number of casualties peaks in the EF3 and EF4 categories. Casualtyproducing EF3+ tornadoes are rare in the West. 
Casualty counts are highest in the South. Alabama has the most casualties $(3,937)$ followed by Oklahoma (2,500), Missouri $(2,025)$, Arkansas $(1,759)$, Texas $(1,704)$, and Tennessee $(1,678)$. Rounding out the top ten are Georgia $(1,610)$, Mississippi $(1,400)$, Kentucky $(1,051)$, and North Carolina (985). Massachusetts, ranks 22nd, stands out in New England with 232 casualties from only three tornadoes. Alabama leads the nation in both injuries and deaths with Oklahoma in 2nd with injuries and Missouri in 2nd with deaths (Fig. 2).

\section{b. Population}

From the tornado track we create a damage path based on the width variable given in the database and then estimate the total number of people within the path. Population data are obtained from the Gridded Population of the World, version four (GPW, v4) from the Socioeconomic Data and Applications Center at Columbia University, USA. The database contain decennial census density estimates for 1990, 2000, and 2010 represented as people $/ \mathrm{km}^{2}$. Densities are based on residential population. The native cell resolution is $.0083^{\circ}$ latitude/longitude, which at $36^{\circ} \mathrm{N}$ latitude means a cell having the dimension of .9 $\mathrm{km}$ in the north-south direction and $.7 \mathrm{~km}$ in the east-west direction. For each tornado we assign the population density corresponding to the closest decennial estimate so, for example, a tornado that occurred in 1996 uses the 2000 decennial estimate while a tornado that occurred in 2012 uses the 2010 estimate.

For the set of 2208 tornadoes with at least one casualty the median population density per tornado is 31.3 people $/ \mathrm{km}^{2}$ with an inter-quartile range between 9.6 and 136 people $/ \mathrm{km}^{2}$. We estimate the EF2 Brooklyn, NY tornado of 8 August 2007 that injured 9 had the highest population density in its path at 13,949 people $/ \mathrm{km}^{2}$. Of the top ten casualty-producing tornadoes with the highest population densities three occurred in New York, two occurred in Florida, and two occurred in California. Pennsylvania, Massachusetts, and Texas each had one. There are 16 casualty-producing 
tornadoes that occurred over areas without people highlighting the fact that population data is residential and casualties can occur when people are at work or in transit.

The U.S. Census Bureau defines 'urban' using population density at the block level. Roughly speaking an urban block has a density of at least 386 people $/ \mathrm{km}^{2}$ otherwise it is 'rural'. Here population density is estimated within the tornado path and the rural-urban gradient is defined across a range of densities.

The distribution of population and population density in the path of tornadoes by EF rating is shown in Fig. 2. We estimate that about 2.5 million people have been within the path of a tornado and 1.5 million people within the path of a casualty-producing tornado. Because of their frequency and path area, EF1 tornadoes account for the largest accumulated number of people at risk. But given a casualty-producing tornado, it is the EF3 tornadoes that, as a group, affected the most people. The number of people affected is a strong function of EF rating since more damaging tornadoes tend to have larger damage paths (Brooks 2004; Elsner et al. 2014; Ashley and Strader 2016) There is no strong relationship between median population density and EF rating. There are thirty non-casualty-producing tornadoes without an EF rating with an estimated total population within the paths of thirteen people.

For comparison, Table 3 lists cities and population densities by states in the South.

\section{c. Energy dissipation}

Tornadoes dissipate a large amount of atmospheric energy (Fricker et al. 2014, 2017). Following what was done with hurricanes (Emanuel 2005), here per tornado energy dissipation (power) is computed as

$$
E=A_{p} \rho \sum_{j=0}^{J} w_{j} v_{j}^{3}
$$


where $A_{p}$ is the area of the path, $\rho$ is area density $\left[1 \mathrm{~kg} / \mathrm{m}^{3}\right] v_{j}$ is the midpoint wind speed for each rating, and $w_{j}$ is the corresponding fraction of path area by $\mathrm{EF}$ rating. The fraction of path area is that recommended by the U.S. Nuclear Regulatory Commission (see Fricker and Elsner (2015)), which combines a Rankine vortex with empirical estimates (Ramsdell and Rishel 2007).

Threshold wind speeds $\left(\mathrm{m} \mathrm{s}^{-1}\right)$ for the EF ratings are a three second gust. With no upper bound on the EF5 wind speeds, the midpoint wind speed is set at $97 \mathrm{~m} \mathrm{~s}^{-1}\left(7.5 \mathrm{~m} \mathrm{~s}^{-1}\right.$ above the threshold wind speed consistent with the EF4 midpoint speed relative to its threshold).

There are no statistically significant upward trends in the annual average per-tornado population exposed or energy dissipated although 2011 was unusually high for both variables (Fig. 3). 2010 was unusually high for energy dissipation, but not population exposed, while 2013 was unusually high for population exposed, but not energy dissipation. The distributions of per-tornado population density and energy dissipation are approximately normal on a logarithmic scale.

\section{Results}

a. Descriptive statistics

For the set of 2208 tornadoes with at least one casualty the median population density per tornado is 31.3 people $/ \mathrm{km}^{2}$ with an inter-quartile range between 9.6 and 136 people $/ \mathrm{km}^{2}$. Over the same set of tornadoes the median energy dissipation is 95.5 gigawatt with an inter-quartile range between 14 and 511 GW. The Tallulah-Yazoo City-Durant tornado (Louisiana and Mississippi) of 24 April 2010 that killed ten and injured 146 has the highest energy dissipation at $66.2 \mathrm{PW}$. There are seven orders of magnitude separating the lowest from the highest per-tornado energy dissipation. There are five orders of magnitude separating the lowest from highest per-tornado population density (Table 4). 
As shown in Fricker et al. (2017), given a tornado with at least one casualty, the number of casualties increases with the estimated number of people in the path and with the energy dissipation (Fig. 4). The bi-variate relationships are both significant with the casualty-energy relationship stronger.

Energy dissipation depends on the EF rating. Tornadoes that hit more targets in developed areas (built environments) have the potential to be rated higher all else being equal because the rating comes from the worst damage. In built environments with more targets there are more people so energy dissipation might contain some population effect. However, the correlation between energy dissipation and population density is small (and negative) indicating this is not a problem.

\section{b. Model}

For the set of tornadoes with at least one casualty, the mean and variance of the counts are 11.8 and 2826, respectively suggesting a negative binomial model (Simmons and Sutter 2005; Fricker et al. 2017) expressed as

$$
C \sim \operatorname{NegBin}(\hat{\mu}, n)
$$

where $\hat{\mu}$ is the per-tornado casualty rate conditional on at least one casualty and $n$ is the size parameter for the negative binomial distribution.

As in Fricker et al. (2017), the logarithm of the casualty rate is expressed statistically as a linear combination of the logarithm of the population density $(P)$ and the logarithm of the energy dissipation $(E)$. Assuming no interaction between population and energy dissipation, Fricker et al. (2017) show that the coefficient on the energy dissipation term (energy elasticity) is significantly larger than the coefficient on the population term. On average a doubling of tornado energy will result in more casualties than a doubling of population. While this result is important in comparing 
the relative contributions of tornado energy and population exposure on the casualty rate, it is predicated on the assumption that there is no interaction between them.

Here we relax this assumption and add an interaction term to the model. This allows us to investigate to what extent population conditions the effect of energy on the casualty rate. Statistically, the model is expressed as

$$
\log (\hat{\mu})=\hat{\beta}_{0}+\hat{\beta}_{1} \log (P)+\hat{\beta}_{2} \log (E)+\hat{\beta}_{3} \log (P): \log (E)
$$

where the coefficients $\hat{\beta}_{1}$ and $\hat{\beta}_{2}$ are the population and energy elasticities, respectively and the coefficient $\hat{\beta}_{3}$ is the coefficient on the interaction term. The model is fit to the set of per-tornado casualties and the coefficients listed in Table 5.

Interest focuses on the interaction term coefficient, which is positive and significant $\left[\beta_{3}=\right.$ $+.22 \pm .049$ (s.e.)] indicating the casualty rate depends on energy dissipation and the casualty rate increases with population density. In short, the effect of energy on the casualty rate (energy elasticity) increases with population (Fig. 5). The energy elasticity is significantly above zero for densities somewhat less than one person $/ \mathrm{km}^{2}$. For tornadoes affecting more urbanized areas (population densities exceeding 1000 people $/ \mathrm{km}^{2}$ ), energy elasticity is near one. Thus, population conditions the effect of energy on the casualty rate. By symmetry this means energy conditions the effect of population (Berry et al. 2012). The population elasticity is significantly above zero for energy dissipation above about $5 \mathrm{GW}$ and reaches one at about $10 \mathrm{PW}$ of energy dissipation. The increasing energy elasticity with greater population is quantified in Figure 6 with predictions of the casualty rate at given population densities. For population densities of one person $/ \mathrm{km}^{2}$ the casualty rate increases from about one at an energy dissipation of $.1 \mathrm{GW}$ to about seven at an energy dissipation of $10 \mathrm{PW}$. For an order of magnitude increase in the number of people under the path, the casualty rate increases from about one at an energy dissipation of $.1 \mathrm{GW}$ to about 18 
at an energy dissipation of $10 \mathrm{PW}$. For densities at or exceeding 10 people $/ \mathrm{km}^{2}$ each factor-of-ten increase in energy significantly increases the casualty rate above the previous level.

\section{c. Interaction by state}

Here we examine regional variations in the level and significance of the population-energy interaction on casualties by refitting the model using tornadoes whose genesis occurred within each state. Table 6 lists the interaction coefficient in decreasing order and the associate $p$-values by states in states with at least 70 casualty-producing tornadoes. Interaction between energy and population is most pronounced (statistically and substantially) in Arkansas and the surrounding states of the Mid South including Tennessee and Missouri. Marginally significant interaction ( $p$ value $<.15)$ is noted for casualties occurring from tornadoes in other states in the South including Kentucky, Oklahoma, Alabama, Mississippi, Texas, and Louisiana, but the effect is less substantial. Illinois also has a significant interaction but not North Carolina, Georgia, or Florida. The top ten states by strength of interaction do not change when the threshold number of tornadoes is decreased to 50 .

To better articulate these regional differences, we compare the conditional energy elasticities between states having substantial and significant interaction (AR, TN, MO) with those having insignificant interaction. That is, we leave out states having significant, but weaker interactions. Results are shown in Figure 7.

There is a significant interaction between energy and population on casualties for tornadoes occurring over the Mid South but not elsewhere. In both regions the energy elasticity values for tornadoes over rural areas show about a $25 \%\left[\left(2^{32}-1\right) \times 100 \%\right]$ increase in the casualty rate for a doubling of energy dissipation. For tornadoes in more urbanized areas primarily across Arkansas, Tennessee, and Missouri a doubling of energy dissipation results in a substantially and significantly 
higher increase at about a 300\%. In more urban areas across the Great Lakes, Northeast, and parts of the Southeast (Florida and Georgia) a doubling of energy dissipation results in higher casualty rates compared with more rural areas at about $70 \%$, but the difference is not significant. While others have noted that cities can be particular vulnerable to tornado casualties, our result shows that higher urban vulnerability relative to rural vulnerability is largely confined to the Mid South.

\section{d. Day and night casualty rates}

The higher casualty rate might be due to the greater percentage of nighttime casualty-producing tornadoes in the Mid South (Ashley et al. 2008). The number of nighttime casualty-producing tornadoes is 878 and the number of daytime casualty-producing tornadoes is 1330 . More than one and a half times as many occur between sunrise and sunset as between sunset and sunrise. This is consistent with the diurnal cycle of tornado activity (Ashley et al. 2008), which tends to peak in the late afternoon and early evening hours and is at a minimum in the early morning following the diurnal cycle of convective instability (Kis and Straka 2010). The chance that any tornado will produce a casualty is higher at night (Ashley et al. 2008).

Over the period 1995-2016 the empirical probability that a tornado results in at least one casualty is $6.9 \%$ between sunrise and sunset but increases to $11.7 \%$ between sunset and sunrise and the probability that a tornado results in at least one fatality is $1.3 \%$ during the day but increases to $3 \%$ at night. However, we note that the per-tornado casualty rate is 12.8 during the day compared to only 10.2 at night. There are $25 \%$ fewer casualties, and $11 \%$ fewer fatalities, per casualtyproducing tornado at night than during the day.

Model results show that casualty rates are not significantly higher at night across a broad range of tornado energies and population exposures (Fig. 8). Stronger tornadoes occurring over less populated areas of the Mid South tend to have a relatively lower nocturnal casualty rate. Thus 
the relatively higher incidence of nocturnal tornadoes across the Mid South does not explain the rural-urban gradient in vulnerability. These day-night results are unaffected by removing the two largest casualty events.

\section{e. Workday and weekend casualty rates}

Consistent with expectations based on higher risk information flows during the week and with better access to permanent buildings (businesses and schools), Zahran et al. (2013) showed that tornadoes occurring on workdays are significantly less lethal than those occurring on weekends. We examine this finding for the Mid South. Since weekend days make up fewer than $30 \%$ of all days we include the surrounding states of Kentucky, Oklahoma, Alabama, Mississippi, Texas, and Louisiana in our delineation of the Mid South. Model results show that casualty rates are generally lower during the week (Fig. 9) consistent with the findings of Zahran et al. (2013). This is particularly true where there are more people. Interestingly, the weekday-weekend casualty differential exists elsewhere but it is not significant.

\section{Discussion}

Results from a model of casualties show a substantial and statistically significant variable interaction indicating that the percent change with energy in the rate of casualties increases with population density. The model reveals a gradient in tornado vulnerability across population density. Fitting separate models using casualty-producing tornadoes originating in each state reveals that vulnerability gradient is significant only in the Mid South. Specifically casualty rates are substantially higher in more urbanized areas of the Mid South than in similar urbanized areas of Indiana or Ohio controlling for energy. 
As an example, results from the model show that for an average city in Indiana with a population density of 679 people $/ \mathrm{km}^{2}$ the energy elasticity is $62 \%$. A tornado that causes 10 casualties would cause 16 casualties if it where twice as strong. In contrast for a city like Little Rock, Arkansas with a population density of about the average for the state of Indiana (641 people/ $\mathrm{km}^{2}$ ), the energy elasticity is $225 \%$ so a tornado that causes 10 casualties would cause 32 casualties if it where twice as strong. Thus Little Rock, Arkansas is twice as vulnerable to casualties from tornadoes when compared with a similarly sized city (in terms of population density) in Indiana.

Additional results arising by fitting the model to subsets of the data show casualty rates are not significantly different at night through a broad range of energy dissipation values and population exposures. The chance of a random tornado producing a casualty is apparently higher at night but the casualty rate per casualty-producing tornado is somewhat lower. Thus the higher relative incidence of nocturnal tornadoes across the Mid South does not explain the rural-urban gradient in vulnerability. Also, casualty rates are higher during the weekend than during the week but the differential is only substantial and significant in more urbanized areas in the Mid South.

While the approach taken here is able to articulate tornado vulnerability in terms of casualty rates while controlling for tornado strength, the findings are largely consistent with others. For instance, Donner (2007) finds that census tracts with larger proportion of rural residents tend to be less vulnerable to fatalities and injuries. Results here show the same. Tornadoes occurring over rural areas are less vulnerable (as a percentage change for a change in energy) than areas with more people. But this rural-urban vulnerability gradient is confined to the Mid South and is most significant only for Arkansas, Tennessee, and Missouri. As mentioned, Donner (2007) speculates that the culture of rural America might foster better resilience. However, findings here show that more urbanized areas have the same vulnerability as rural areas except in the Mid South so the explanation is, at best, incomplete. He further suggests that urban areas might have greater 
vulnerability due to the presence of the built environment, which limits visibility and thus the potential for visual confirmation. Again, this explanation would not predict the absence of a significant rural-urban vulnerability gradient in tornadoes occurring outside the Mid South.

Also, Zahran et al. (2013) finds that tornado casualties are more common over the weekend. Results here show the same. On average, in regions where population densities exceed 100 people $/ \mathrm{km}^{2}$, significantly higher casualty rates are found during the weekend than during the week. But this statistically significant daily variation is confined to the greater Mid South. The most common protective measure against a tornado casualty is to shelter-in-place. Donner (2007) and Zahran et al. (2013) speculate that work and school buildings provide a more substantial place to shelter than at home during the weekend and that risk information is more efficiently communicated at work and school. However, we find that casualty rates are somewhat higher during the day than at night when folks are more likely to be at home, so these explanations are incomplete. Most motor vehicle fatalities involving tornadoes occur in the South (Paulikas and Schmidlin 2017), but folks living in rural areas drive greater distances than those in towns or cities and more driving is done during the week than on weekends (Triplett et al. 2015).

According to Zahran et al. (2013), the daily variation in casualty rates should be lower during the summer with the increasing loss of risk information, and when people are less likely to be in tornado-resistant buildings like businesses and schools. But, since his model does not account for spatial variability, this result is explained by the northward migration of tornadoes to areas outside the Mid South during the summer where there is less difference between weekdays and weekends. Further the results here show that Illinois and Alabama have statistically similar model coefficients indicating that different coping mechanisms for people in the South (Sims and Baumann 1972) are likely not a significant factor in casualty rates more recently. 
Mobile homes are particularly dangerous in a tornado with the likelihood of casualties substantially higher than in a permanent home (Glass et al. 1980; Eidson et al. 1990; Brooks and Doswell 2002; Simmons and Sutter 2005; Ashley et al. 2008). While there are more people living in manufactured homes in the South than elsewhere (Ashley 2007), the attribution of the rural-urban tornado vulnerability gradient to mobile home frequency is problematic. First, according to Sutter and Simmons (2010) just two states, Florida and Georgia, account for 30\% of all mobile home tornado fatalities in the United States. Neither Florida nor Georgia have a substantial rural-urban vulnerability gradient. Second, South Carolina and North Carolina have the largest percentage of mobile homes (ACS 2004) but not substantial vulnerability gradients. Finally, the percentage of manufactured homes is higher in areas with lower population density (Nitschke 2004), a gradient that is directed opposite to the direction of the vulnerability gradient. Thus while mobile homes are certainly a significant factor in explaining tornado casualties, their spatial distribution does not explain the spatial distribution of the vulnerability gradient.

\section{a. Suburban and exurban elderly}

Why are urbanized areas in the Mid South more vulnerable to tornado casualties than rural areas there and elsewhere? Age increases the odds of getting hurt or killed in a tornado (Glass et al. 1980; Eidson et al. 1990; Brown et al. 2002) and hurricane (Brunkard et al. 2008) and may help with the explanation. The percentage of fatalities of those over age 50 is higher than the percent of the population of that age (Merrell et al. 2005; Ashley 2007). According to Paul and Stimers (2014) the elderly ( $65 \mathrm{yr}$ and older) accounted for more than a third of tornado fatalities in the 22 May 2011 Joplin, MO tornado. The percentage of elderly in Joplin was 14.8\% (2010) but they experienced more than three times as many deaths as the total population of this cohort (Paul and Stimers 2014). According to the National Centers for Environmental Information more than $71 \%$ 
of the fatalities in the Joplin tornado were people 45 years old or older. In contrast $50 \%$ of the fatalities in the Tuscaloosa-Birmingham tornado were people in that same age range (National Centers for Environmental Information 2017).

Arkansas and Missouri rank high in the percentage of people over 65 (Table 5). Tennessee is near the middle. Georgia is very low and so is Louisiana. The spatial distribution of percent elderly appears to match the spatial distribution of the rural-urban vulnerability gradient. Indeed, the correlation between the percent elderly given in the 2010 Census (Howden and Meyer 2011) and the interaction coefficient in the casualty model across the twelve states with at least 70 casualtyproducing tornadoes is $+.69[+.19,+.90,95 \%$ uncertainty interval]. The percentage of disabled (under 65) is also positively correlated with vulnerability suggesting that personal mobility might be one casual factor.

But state-level demographics can be misleading as the results show that it is the more urbanized areas with the greater vulnerability. The 2010 census data for the number of elderly in towns and cities with at least 10,000 people and using a threshold of $18 \%$ for percent $65+$ shows there are 33 cities/towns in the four states of the Mid South (Arkansas, Tennessee, Missouri, and Kentucky) meeting these criteria compared to only 15 in the four states of the South (Georgia, Alabama, Mississippi, and Louisiana). The total elderly in these more urbanized areas total 125,198 and 48,720 for the Mid South and South, respectively.

Being elderly is a statistical determinant of tornado vulnerability. If there is causality it might be related to older people being less mobile and more likely to have health issues (Dixon and Moore 2012; Cutter et al. 2000; Kilijanek and Drabek 1979) limiting their ability to seek adequate shelter and to perform labor intensive measures related to prevention. Moreover, elderly living on fixed incomes may lack the financial resources needed to upgrade their homes to better withstand tornado winds. With an aging population and more folks retiring to the South (not just to Florida) 
vulnerability might well increase in the future. Indeed over the past seven years casualty rates have decreased across the United States but not across the Mid South (Fig 10).

\section{Conclusions}

Tornado casualty counts from the SPC tornado record over the period 1995-2016 are fit to a model with total energy dissipation and population density under the path as independent variables. Model results quantify the interactions between population and energy on tornado casualty counts elucidating where and when communities are particularly vulnerable. The main findings are:

- More urbanized areas of the Mid South are substantially and significantly more vulnerable to casualties from tornadoes than elsewhere in the country.

- Casualty rates are significantly higher during the weekend for tornadoes occurring over the Mid South, but not elsewhere.

- Night and day casualty rates are similar regardless of where they occur.

- At the state level, increased vulnerability to casualties from tornadoes occurring in more urbanized areas correspond with higher percentages of elderly people.

This is the first study to examine the interaction of population and tornado strength on tornado casualties. To better articulate vulnerable subpopulations future work will focus on quantifying the interaction of specific demographics and tornado strength and how those interactions vary spatially and temporally.

Acknowledgments. This work was initiated after discussions with William D. Berry in the Department of Political Science at Florida State University. 


\section{References}

ACS, 2004: Percent of housing units that are mobile homes by state. Tech. rep., American Community Survey. URL www.statemaster.com/graph/hou_per_of_hou_uni_tha_are_mob_ hom-housing-percent-units-mobile-homes\#.

Ashley, W., 2007: Spatial and temporal analysis of tornado fatalities in the United States: 18802005. Weather and Forecasting, 22, 1214-1228.

Ashley, W. S., A. J. Krmenec, and R. Schwantes, 2008: Vulnerability due to nocturnal tornadoes. Weather and Forecasting, 23, 795-807.

Ashley, W. S., and S. M. Strader, 2016: Recipe for disaster: How the dynamic ingredients of risk and exposure are changing the tornado disaster landscape. Bulletin of the American Meteorological Society, 97, 767-786.

Berry, W. D., M. Golder, and D. Milton, 2012: Improving tests of theories positing interaction. The Journal of Politics, 74 (3), 653-671, doi:10.1017/S0022381612000199.

Bohonos, J. J., and D. E. Hogan, 1999: The medical impact of tornadoes in North America. The Journal of Emergency Medicine, 17, 67-73.

Boruff, B. J., J. A. Easoz, S. D. Jones, H. R. Landry, J. D. Mitchem, and S. L. Cutter, 2003: Tornado hazards in the United States. Climate Research, 24, 103-117.

Brooks, H. E., 2004: On the relationship of tornado path length and width to intensity. Weather and Forecasting, 19, 310-319.

Brooks, H. E., and C. A. Doswell, 2002: Deaths in the 3 May 1999 Oklahoma City tornado from a historical perspective. Weather and Forecasting, 17, 354-361. 
Brown, S., P. Archer, E. Kruger, and S. Mallonee, 2002: Tornado-Related Deaths and Injuries in Oklahoma due to the 3 May 1999 Tornadoes. Weather and Forecasting, 17, 343-353.

Brunkard, J., G. Namulanda, and R. Ratard, 2008: Hurricane katrina deaths, louisiana, 2005. Disaster Medicine and Public Health Preparedness, 2 (4), 215-223, doi:10.1097/DMP. 0b013e31818aaf55.

CDC, 2012: Tornado-Related Fatalities Five States, Southeastern United States, April 2528, 2011. Tech. rep., Centers for Disease Control and Prevention. URL www.cdc.gov/mmwr/preview/ mmwrhtml/mm6128a3.htm.

Cutter, S., J. T. Mitchell, and M. S. Scott, 2000: Revealing the vulnerability of people and places: A case study of Georgetown County, South Carolina. Annals of the Association of American Geographers, 90, 13-37.

Dixon, R. W., and T. W. Moore, 2012: Tornado vulnerability in Texas. Weather, Climate, and Society, 4, 59-68.

Donner, W. R., 2007: The political ecology of disaster: An analysis of factors influencing U.S. tornado fatalities and injuries, 1998-2000. Demography, 44 (3), 669-685, doi:10.1353/dem. 2007.0024, URL https://doi.org/10.1353\%2Fdem.2007.0024.

Eidson, M., J. A. Lybarger, J. E. Parsons, J. N. MacCormack, and J. I. Freeman, 1990: Risk factors for tornado injuries. International Journal of Epidemiology, 19, 1051-1056.

Elsner, J. B., T. H. Jagger, H. M. Widen, and D. R. Chavas, 2014: Daily tornado frequency distributions in the United States. Environmental Research Letters, 9 (2), 024018.

Emanuel, K., 2005: Increasing destructiveness of tropical cyclones over the past 30 years. Nature, 436, 686-688. 
Fricker, T., and J. B. Elsner, 2015: Kinetic energy of tornadoes in the United States. PLoSONE, 10, e0131 090, doi:10.1371/journal.pone.0131090.

Fricker, T., J. B. Elsner, P. Camp, and T. H. Jagger, 2014: Empirical estimates of kinetic energy from some recent U.S. tornadoes. Geophysical Research Letters, 41, 4340-4346.

Fricker, T., J. B. Elsner, and T. H. Jagger, 2017: Population and energy elasticity of tornado casualties. Geophysical Research Letters, 44, 3941-3949, doi:10.1002/2017GL073093.

Glass, R. I., R. B. Craven, D. J. Bregman, B. J. Stoll, N. Horowitz, P. Kerndt, and J. Winkle, 1980: Injuries from the Wichita Falls tornado: Implications for prevention. Science, 207, 734-738.

Greenough, G., M. McGeehin, S. M. Bernard, J. Trtanj, J. Riad, and D. Engelbert, 2001: The potential impacts of climate variability and change on health impacts of extreme weather events in the United States. Environmental Health Perspectives, 109, 191-198.

Howden, L. M., and J. A. Meyer, 2011: Age and sex composition: 2010. Tech. rep., United States Census Bureau. URL https://www.census.gov/population/www/socdemo/age/.

Kilijanek, T., and T. Drabek, 1979: Assessing long-term impacts of a natural disaster: A focus on the elderly. Gerontologist, 19, 555-566.

Kis, A. K., and J. M. Straka, 2010: Nocturnal tornado climatology. Weather and Forecasting, 25 (2), 545-561.

Lim, J., S. Loveridge, R. Shupp, and M. Skidmore, 2017: Double danger in the double wide: Dimensions of poverty, housing quality and tornado impacts. Regional Science and Urban Economics, 65, 1-15, doi:10.1016/j.regsciurbeco.2017.04.003, URL https://doi.org/10.1016/j. regsciurbeco.2017.04.003. 
Merrell, D., K. M. Simmons, and D. Sutter, 2005: The determinants of tornado casualties and the benefits of tornado shelters. Land Economics, 81, 87-99.

Mileti, D. S., and P. W. O’Brien, 1992: Warnings during disasters: Normalizing communicated risk. Social Problems, 39, 40-57.

National Centers for Environmental Information, 2017: Storm Events Database. URL \{https:// www.ncdc.noaa.gov/stormevents/\}.

National Oceanic and Atmospheric Administration, 2015: National Weather Service Weather Fatality, Injury, and Damage Statistics. URL \{http:/www.nws.noaa.gov/om/hazstats/resources/ weather_fatalities.pdf $\}$.

Nitschke, L., 2004: Manufactured homes a big factor in rural homeownership in U.S. Tech. rep., Population Reference Group. URL www.prb.org/Publications/Articles/2004/ ManufacturedHomesaBigFactorinRuralHomeownershipinUS.aspx.

Paul, B. K., and M. Stimers, 2014: Spatial analyses of the 2011 Joplin tornado mortality: Deaths by interpolated damage zones and location of victims. Weather, Climate, and Society, 6, 161174.

Paulikas, M. J., and T. W. Schmidlin, 2017: US tornado fatalities in motor vehicles (19912015). Natural Hazards, 87, 121-143.

R Core Team, 2016: R: A Language and Environment for Statistical Computing. Vienna, Austria, R Foundation for Statistical Computing, URL https://www.R-project.org/.

Ramsdell, J. V., Jr, and J. P. Rishel, 2007: Tornado Climatology of the Contiguous United States. Tech. Rep. NUREG/CR-4461, PNNL-15112, Pacific Northwest National Laboratory, P.O. Box 999, Richland, WA 99352. 
Simmons, K. M., and D. Sutter, 2005: WSR-88d radar, tornado warnings, and tornado casualties. Weather and Forecasting, 20 (3), 301-310, doi:10.1175/waf857.1, URL https://doi.org/10. 1175\%2Fwaf857.1.

Simmons, K. M., and D. Sutter, 2008: Tornado warnings, lead times, and tornado casualties: An empirical investigation. Weather and Forecasting, 23, 246-258.

Sims, J. H., and D. D. Baumann, 1972: The tornado threat: Coping styles of the North and South. Science, 176, 1386-1392.

Sutter, D., and K. M. Simmons, 2010: Tornado fatalities and mobile homes in the United States. Natural Hazards, 53, 125-137.

Triplett, T., R. Santos, and S. Rosenbloom, 2015: American Driving Survey: Methodology and Year 1 Results, May 2013-2014. Tech. rep., The Urban Institute. URL http://newsroom.aaa.com/wp-content/uploads/2015/04/REPORT_American_Driving_Survey_ Methodology_and_year_1_results_May_2013_to_May_2014.pdf.

Verbout, S. M., H. E. Brooks, L. M. Leslie, and D. M. Schultz, 2006: Evolution of the U.S. tornado database: 1954-2003. Weather and Forecasting, 21, 86-93.

Zahran, S., D. Tavani, and S. Weiler, 2013: Daily variation in natural disaster casualties: Information flows, safety, and opportunity costs in tornado versus hurricane strikes. Risk Analysis, 33, 1265-1280. 
Table 1. Casualties by EF rating. .

Table 2. Distribution of population and population density in the path of tornadoes

Table 3. Example towns and cities by state across a range of population densities. .

Table 4. Descriptive statistics for the variables used in the regression model. MW: megawatt $\left(10^{6} \mathrm{~W}\right), \mathrm{GW}$ : gigawatt $\left(10^{9} \mathrm{~W}\right)$, TW: terawatt $\left(10^{12} \mathrm{~W}\right) \quad$. $\quad . \quad$. $\quad$. 30

Table 5. Table of coefficients for a model fit to the per-tornado casualty counts.

Table 6. Interaction coefficients and associated $p$-value by state. 32 
TABLE 1. Casualties by EF rating.

\begin{tabular}{cccccc}
\hline EF & Casualties & Tornadoes & Fatalities & Injuries & Avg. Casualties/Tor. \\
\hline 0 & 362 & 183 & 8 & 354 & 2.0 \\
1 & 2300 & 750 & 79 & 2221 & 3.1 \\
2 & 4888 & 753 & 218 & 4670 & 6.5 \\
3 & 7933 & 392 & 536 & 7397 & 20.2 \\
4 & 7187 & 116 & 457 & 6730 & 62.0 \\
5 & 3298 & 14 & 432 & 2866 & 235.6 \\
\hline
\end{tabular}


TABLE 2. Distribution of population and population density in the path of tornadoes (casualty-producing and all) by EF rating.

\begin{tabular}{|c|c|c|c|c|c|c|}
\hline $\mathrm{EF}$ & Tornadoes & Total People & Avg. No. People/Tor & Median No. People/Tor & Avg. Pop. Density $\left(/ \mathrm{km}^{2}\right)$ & Median Pop. Density $\left(/ \mathrm{km}^{2}\right)$ \\
\hline \multicolumn{7}{|c|}{ Casualty-Producing Tornadoes } \\
\hline 0 & 183 & 9386 & 51 & 4 & 440 & 55 \\
\hline 1 & 750 & 217053 & 289 & 17 & 293 & 37 \\
\hline 3 & 392 & 492471 & 1256 & 261 & 88 & 24 \\
\hline 4 & 116 & 289722 & 2498 & 824 & 103 & 27 \\
\hline 5 & 14 & 89981 & 6427 & 3318 & 82 & 25 \\
\hline 1 & 7463 & 698008 & 94 & 5 & 139 & 14 \\
\hline 2 & 2143 & 633813 & 296 & 29 & 119 & 15 \\
\hline 3 & 620 & 555967 & 897 & 125 & 77 & 17 \\
\hline 4 & 140 & 294953 & 2107 & 550 & 91 & 18 \\
\hline 5 & 14 & 89981 & 6427 & 3318 & 82 & 25 \\
\hline
\end{tabular}


TABLE 3. Example towns and cities by state across a range of population densities.

\begin{tabular}{|c|c|c|c|c|}
\hline \multirow[b]{2}{*}{ State } & \multicolumn{4}{|c|}{ Towns/Cities } \\
\hline & $1-10$ people $/ \mathrm{km}^{2}$ & $10-100$ people $/ \mathrm{km}^{2}$ & $100-500$ people $/ \mathrm{km}^{2}$ & $500-1000$ people $/ \mathrm{km}^{2}$ \\
\hline Arkansas & Scott $(8.4)$ & Zinc (64) & Jonesboro (357) & Little Rock (632) \\
\hline Tennessee & Flat Top Mountain (9.5) & Hillsboro (42) & Gatlinburg (129) & Memphis (770) \\
\hline Missouri & Champ (6.2) & Rensselaer (44) & Clinton (380) & Columbia (660) \\
\hline Alabama & Putnam (7.9) & Hackleburg (37) & Montgomery (478) & Birmingham (551) \\
\hline Mississippi & NA & McLain (49) & Starkville (360) & Oxford (730) \\
\hline Louisiana & Lisbon (5.4) & Monterey (60) & Abita Springs (203) & Lafayette (950) \\
\hline Georgia & Cedar Springs (9.6) & Bluffton (28) & Milledgeville (348) & Albany (535) \\
\hline Oklahoma & Sweetwater (2.1) & Elmer (87) & Norman (255) & Stillwater (620) \\
\hline
\end{tabular}


TABLE 4. Descriptive statistics for the variables used in the regression model. MW: megawatt $\left(10^{6} \mathrm{~W}\right), \mathrm{GW}$ :

541 gigawatt $\left(10^{9} \mathrm{~W}\right)$, TW: terawatt $\left(10^{12} \mathrm{~W}\right)$

\begin{tabular}{|c|c|}
\hline Variable & Value \\
\hline Number of Tornadoes & 2192 \\
\hline Average number of casualties per tornado & 12 \\
\hline Highest number of casualties & 1564 \\
\hline Lowest number of casualties & 1 \\
\hline Standard deviation of casualties & 53 \\
\hline Average population density per tornado (people $/ \mathrm{km}^{2}$ ) & 223 \\
\hline Greatest population density (people $/ \mathrm{km}^{2}$ ) & 13949 \\
\hline Least population density (people $/ \mathrm{km}^{2}$ ) & 0 \\
\hline Standard deviation of population density (people $/ \mathrm{km}^{2}$ ) & 708 \\
\hline Average energy dissipation per tornado (GW) & 855 \\
\hline Maximum energy dissipation (TW) & 66 \\
\hline Minimum energy dissipation (MW) & 5.7 \\
\hline Standard deviation of energy dissipation (TW) & 2.9 \\
\hline
\end{tabular}


TABLE 5. Table of coefficients for a model fit to the per-tornado casualty counts.

\begin{tabular}{rrrrr}
\hline & Estimate & Std. Error & t value & $\operatorname{Pr}(>|\mathrm{t}|)$ \\
\hline$\hat{\beta}_{0}$ & -3.0268 & 0.9606 & -3.15 & 0.0016 \\
$\hat{\beta}_{1}$ & -1.8700 & 0.5281 & -3.54 & 0.0004 \\
$\hat{\beta}_{2}$ & 0.3825 & 0.0868 & 4.41 & $<0.0001$ \\
$\hat{\beta}_{3}$ & 0.2200 & 0.0488 & 4.51 & $<0.0001$
\end{tabular}


TABLE 6. Interaction coefficients and associated $p$-value by state.

\begin{tabular}{clcccc}
\hline Rank & State & $\hat{\beta}_{1}$ & $\hat{\beta}_{1}$ & $\hat{\beta}_{3}$ & $p$-value \\
\hline 1 & Arkansas & -11.353 & -0.207 & 1.023 & 0.000 \\
2 & Tennessee & -7.105 & -0.288 & 0.717 & 0.001 \\
3 & Missouri & -5.965 & 0.084 & 0.607 & 0.010 \\
4 & Kentucky & -5.021 & 0.173 & 0.493 & 0.053 \\
5 & Illinois & -4.111 & 0.271 & 0.417 & 0.021 \\
6 & Oklahoma & -3.625 & 0.315 & 0.404 & 0.023 \\
7 & Alabama & -3.007 & 0.499 & 0.347 & 0.056 \\
8 & Mississippi & -3.291 & 0.454 & 0.329 & 0.106 \\
9 & Texas & -2.844 & 0.135 & 0.308 & 0.001 \\
10 & North Carolina & -2.790 & -0.002 & 0.286 & 0.458 \\
11 & Louisiana & -2.060 & 0.506 & 0.246 & 0.126 \\
12 & Georgia & -0.920 & 0.450 & 0.128 & 0.663 \\
\hline
\end{tabular}




\begin{tabular}{|c|c|c|c|c|}
\hline & & & 2010 & 2016 \\
\hline & State & $\beta_{3}$ & Percent Elderly (65+) & Percent Elderly (65+) \\
\hline 1 & Arkansas & 1.02 & 14.4 & 16.3 \\
\hline 2 & Tennessee & 0.72 & 13.4 & 15.7 \\
\hline 3 & Missouri & 0.61 & 14.0 & 16.1 \\
\hline 4 & Kentucky & 0.49 & 13.3 & 15.6 \\
\hline 5 & Illinois & 0.42 & 12.5 & 16.1 \\
\hline 6 & Oklahoma & 0.40 & 13.5 & 15.0 \\
\hline 7 & Alabama & 0.35 & 13.8 & 16.1 \\
\hline 8 & Mississippi & 0.33 & 12.8 & 15.1 \\
\hline 9 & Texas & 0.31 & 10.3 & 12.0 \\
\hline 10 & North Carolina & 0.29 & 12.9 & 15.5 \\
\hline 11 & Louisiana & 0.25 & 12.3 & 14.4 \\
\hline 12 & Georgia & 0.13 & 10.7 & 13.1 \\
\hline
\end{tabular}




\section{LIST OF FIGURES}

Fig. 1. Location of casualty-producing tornadoes (1995-2016) by EF rating. The size of the circle is proportional to the number of casualties.

Fig. 2. Tornado casualties (top: injuries, bottom: fatalities) by state (1995-2016). All casualties are assigned to the state in which genesis occurred.

Fig. 3. People exposed and energy dissipation for all casualty-producing tornadoes (1995-2016). (A) Annual average number of people exposed per tornado, (B) distribution of per tornado population density, (C) annual average energy dissipation per tornado, and (D) distribution of per tornado energy dissipation.

Fig. 4. Casualties versus population density (A) and energy dissipation (B).

Fig. 5. Marginal effect of (A) population on energy elasticity and (B) energy on population elasticity. The gray ribbon indicates the $95 \%$ uncertainty bound on the slope. Relative percentage of observations are shown as a histogram along the horizontal axis.

Fig. 6. Predicted effect of energy dissipation on casualties for given levels of population density.

The vertical lines indicate the $95 \%$ uncertainty bounds.

Fig. 7. The effect of energy on casualties conditional on population across the Mid South (A) and elsewhere (B). The gray ribbon indicates the $95 \%$ uncertainty bound on the slope.

Fig. 8. Predicted casualty rates daytime versus nighttime for the Mid South (A) and all states (B).

The vertical lines indicate the $95 \%$ uncertainty bounds.

Fig. 9. Predicted casualty rates on week days and on weekends for the greater Mid South (A) and elsewhere (B). The vertical lines indicate the $95 \%$ uncertainty bounds.

Fig. 10. Predicted casualty rates for a tornado with $1 \mathrm{GW}$ of energy dissipation over an area with a population density of 300 people $/ \mathrm{km}^{2}$. The vertical lines indicate the $95 \%$ uncertainty bounds. 
FIG. 1. Location of casualty-producing tornadoes (1995-2016) by EF rating. The size of the circle is proportional to the number of casualties.

EFO

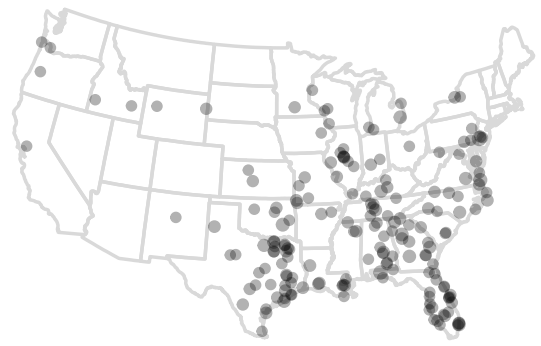

EF2

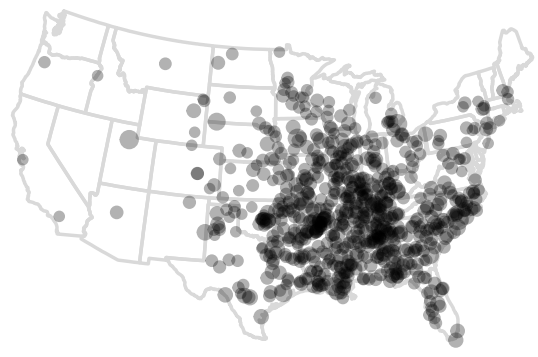

EF4

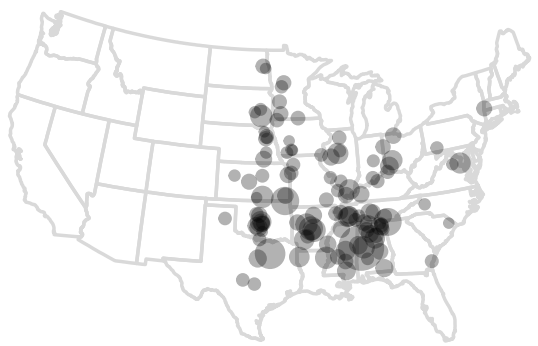

Number of

Casualties
EF1

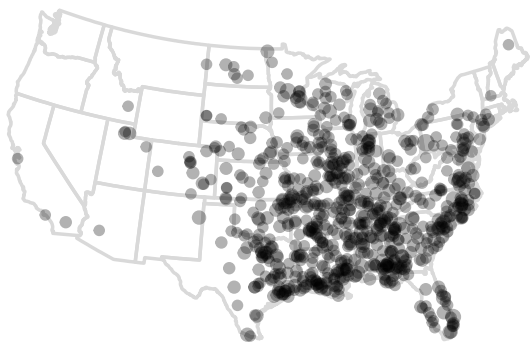

EF3

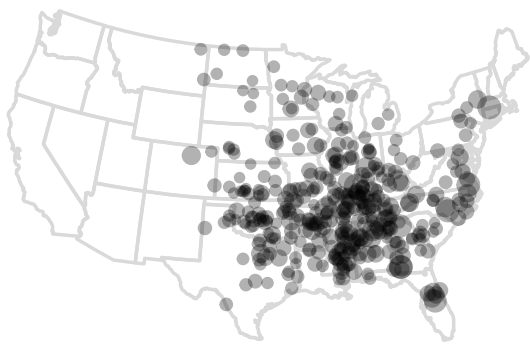

EF5

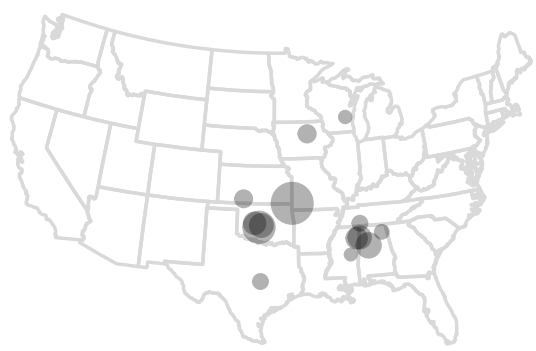

$400 \bigcirc 800 \bigcirc 1200$ 
FIG. 2. Tornado casualties (top: injuries, bottom: fatalities) by state (1995-2016). All casualties are assigned to the state in which genesis occurred.

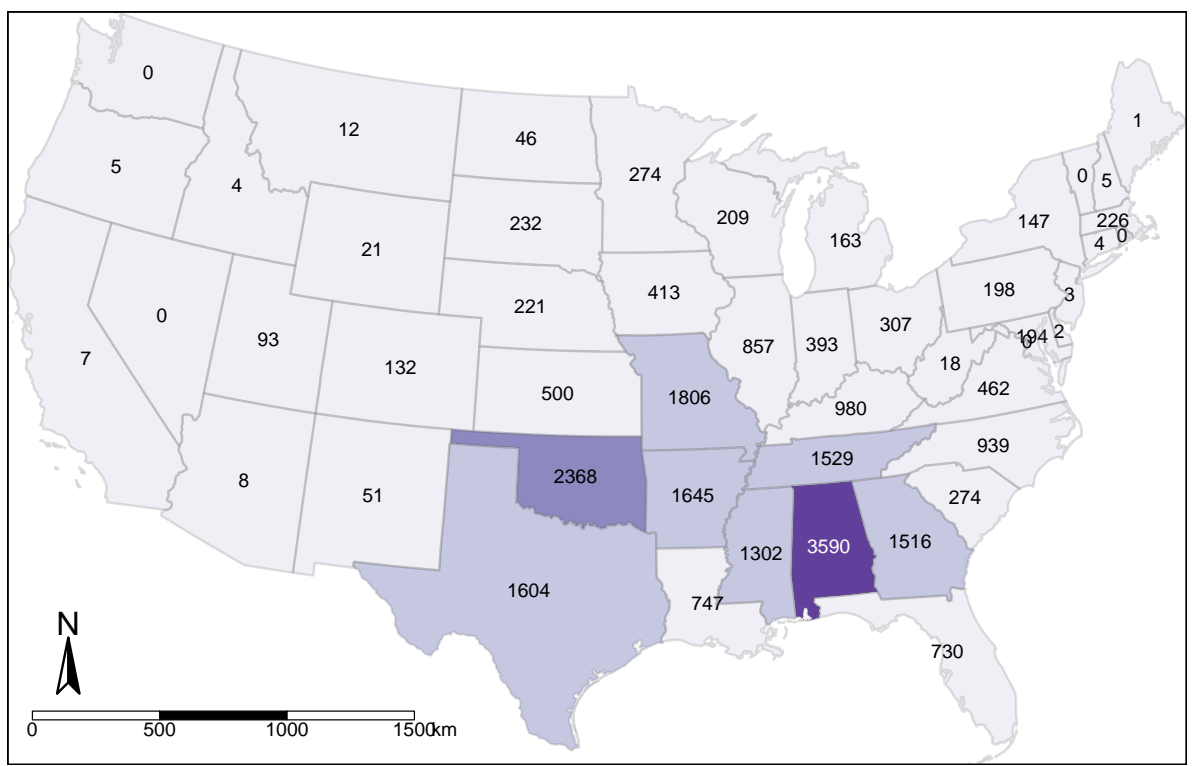

Injuries

0 to 1,000

1,000 to 2,000

2,000 to 3,000

3,000 to 4,000

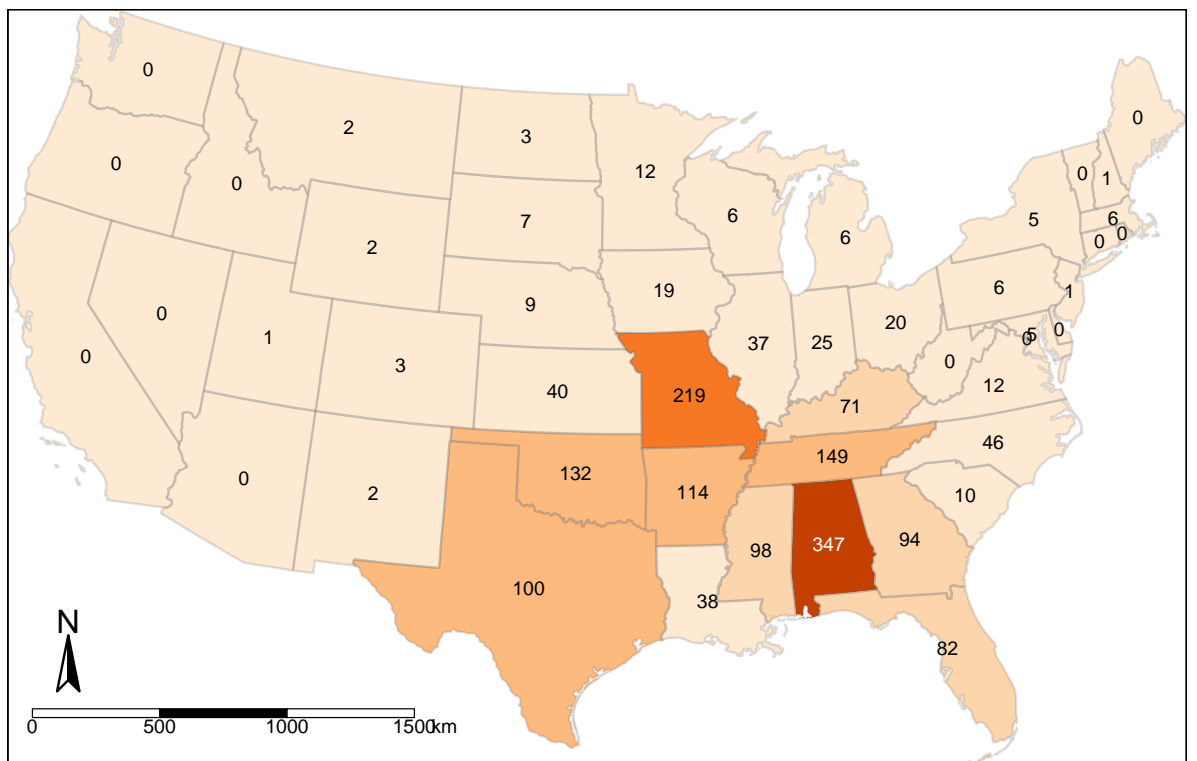

Fatalities

0 to 50

50 to 100

100 to 150

150 to 200

200 to 250

250 to 300 
FIG. 3. People exposed and energy dissipation for all casualty-producing tornadoes (1995-2016). (A) Annual average number of people exposed per tornado, (B) distribution of per tornado population density, (C) annual average energy dissipation per tornado, and (D) distribution of per tornado energy dissipation.

A

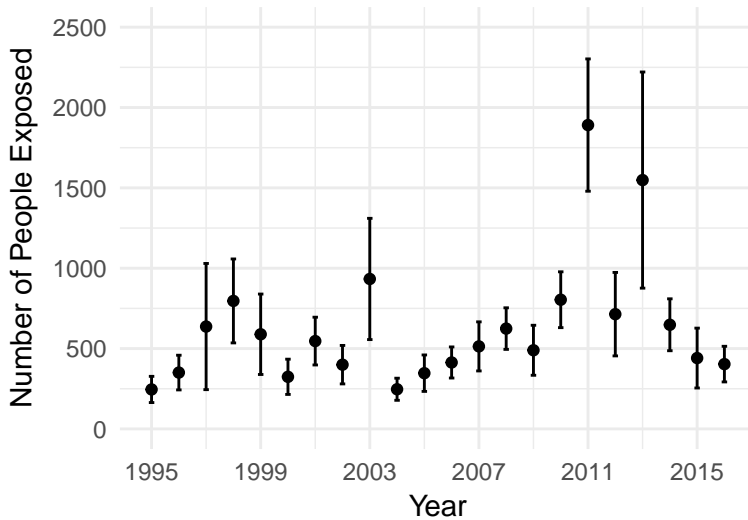

C

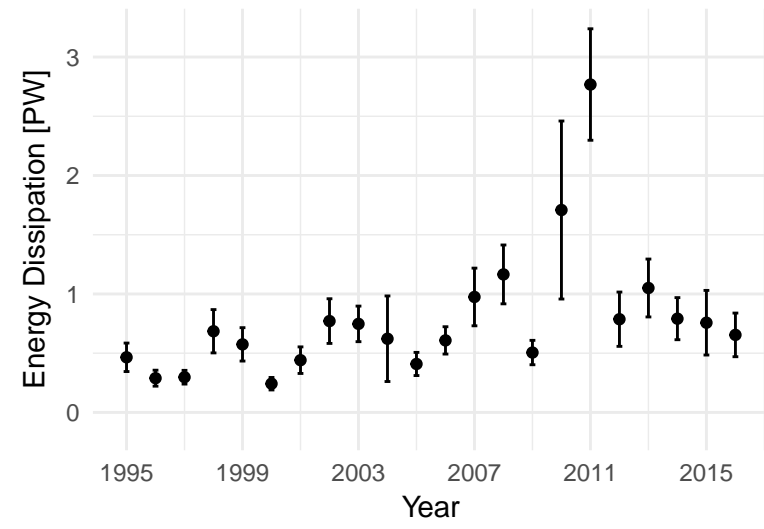

B

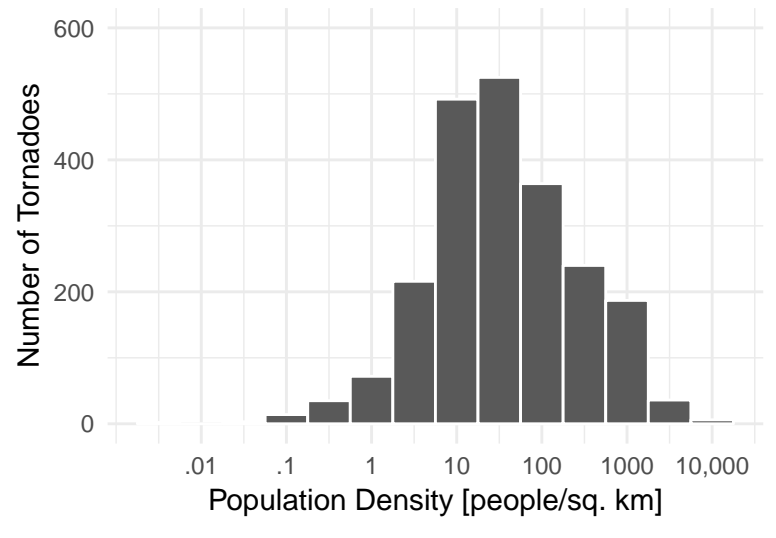

D

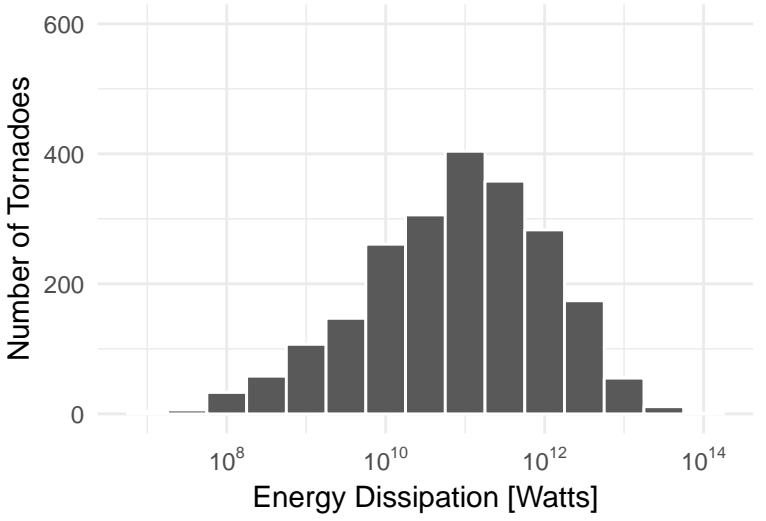


FIG. 4. Casualties versus population density (A) and energy dissipation (B).
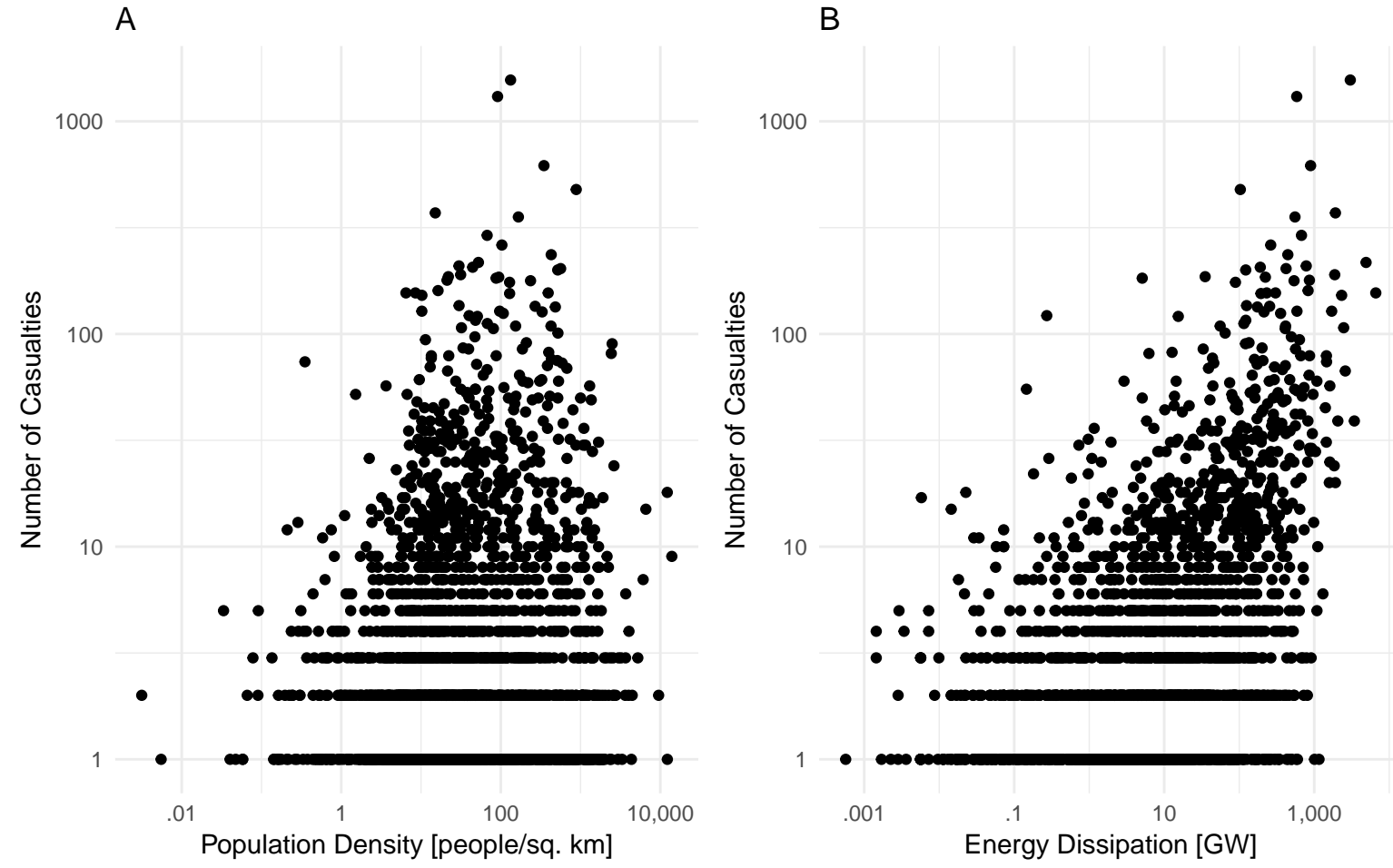
FIG. 5. Marginal effect of (A) population on energy elasticity and (B) energy on population elasticity. The gray ribbon indicates the $95 \%$ uncertainty bound on the slope. Relative percentage of observations are shown as a histogram along the horizontal axis.
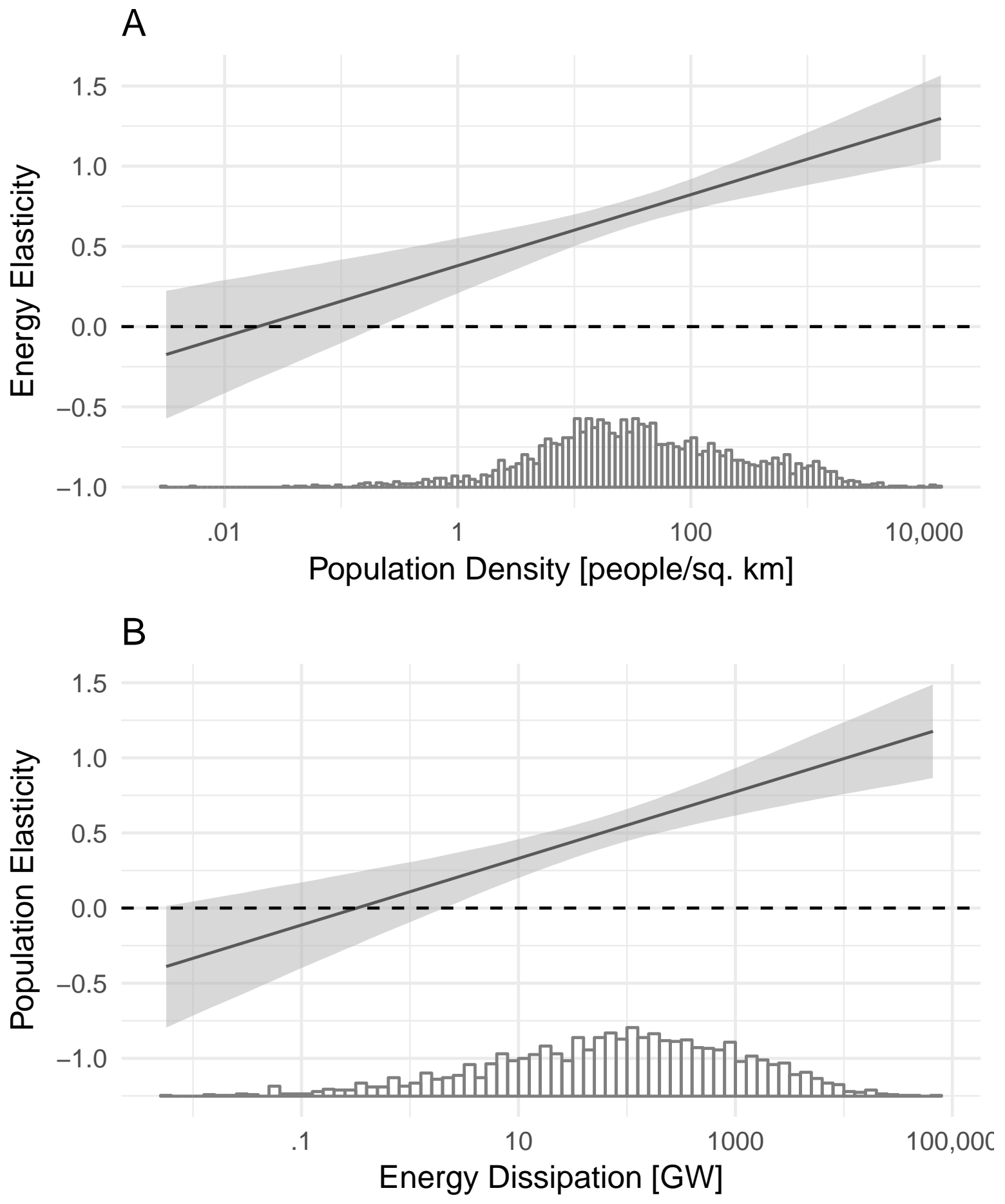
FIG. 6. Predicted effect of energy dissipation on casualties for given levels of population density. The vertical 577 lines indicate the $95 \%$ uncertainty bounds.

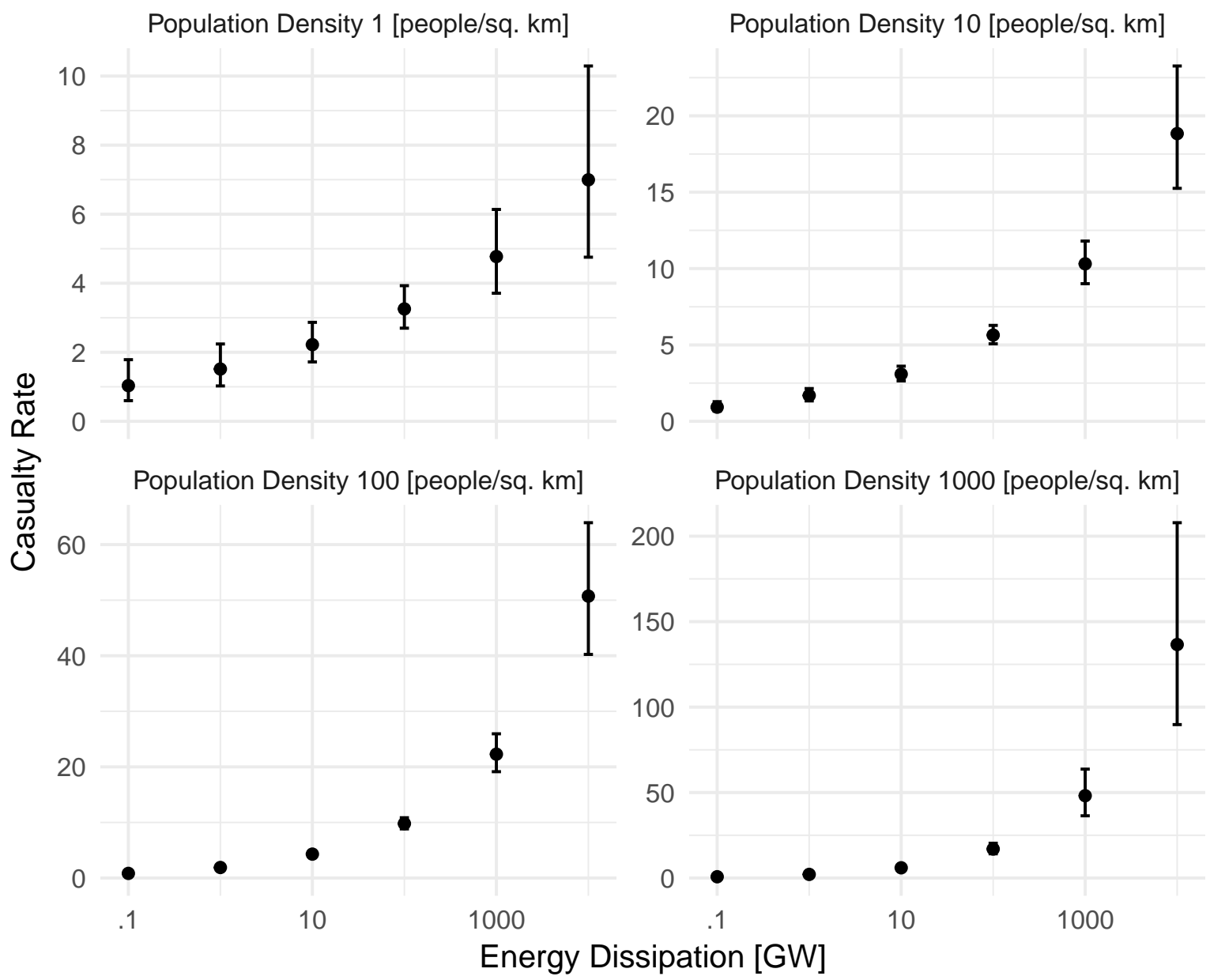


FIG. 7. The effect of energy on casualties conditional on population across the Mid South (A) and elsewhere (B). The gray ribbon indicates the $95 \%$ uncertainty bound on the slope.
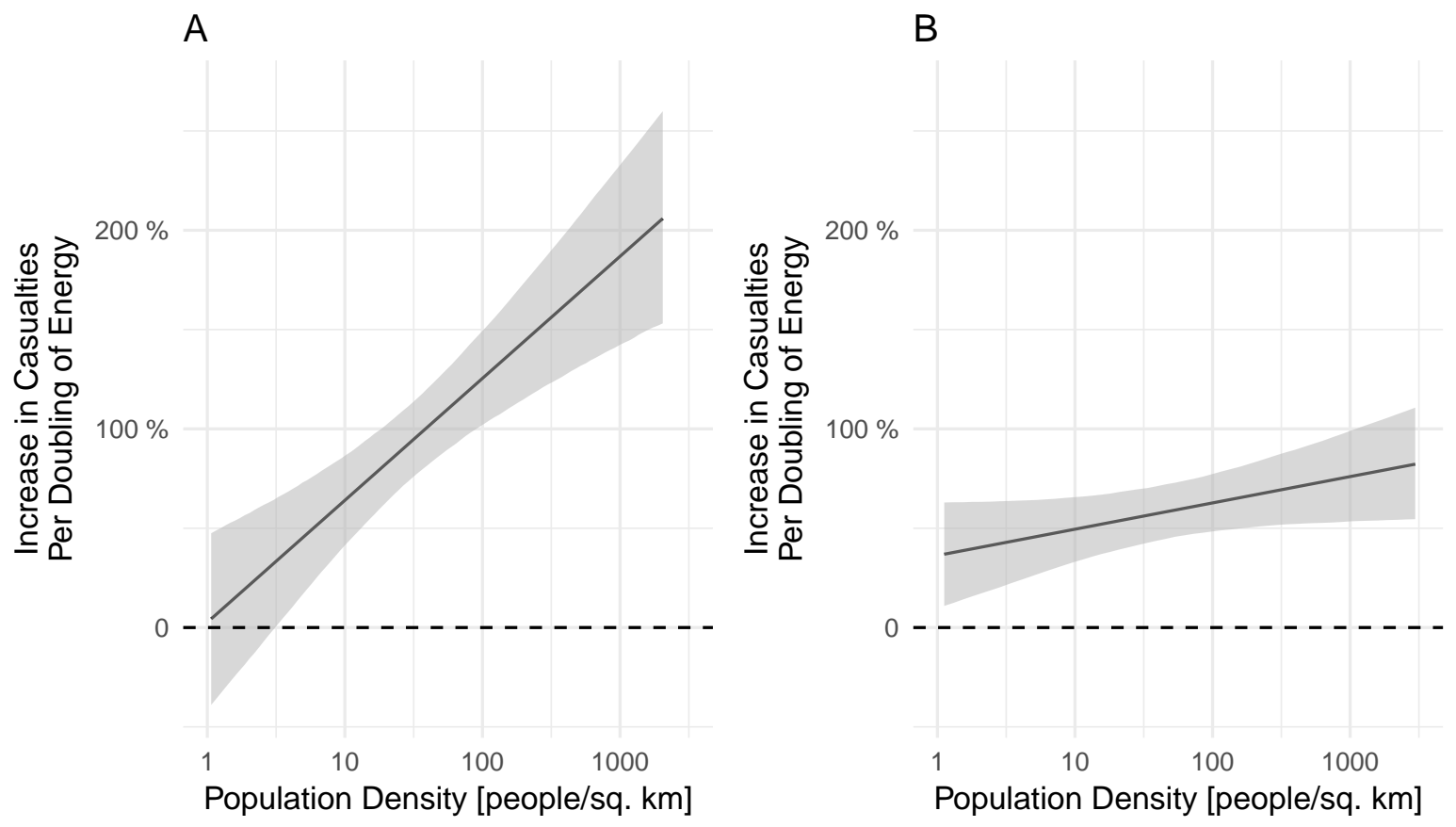
FIG. 8. Predicted casualty rates daytime versus nighttime for the Mid South (A) and all states (B). The vertical 581 lines indicate the $95 \%$ uncertainty bounds.
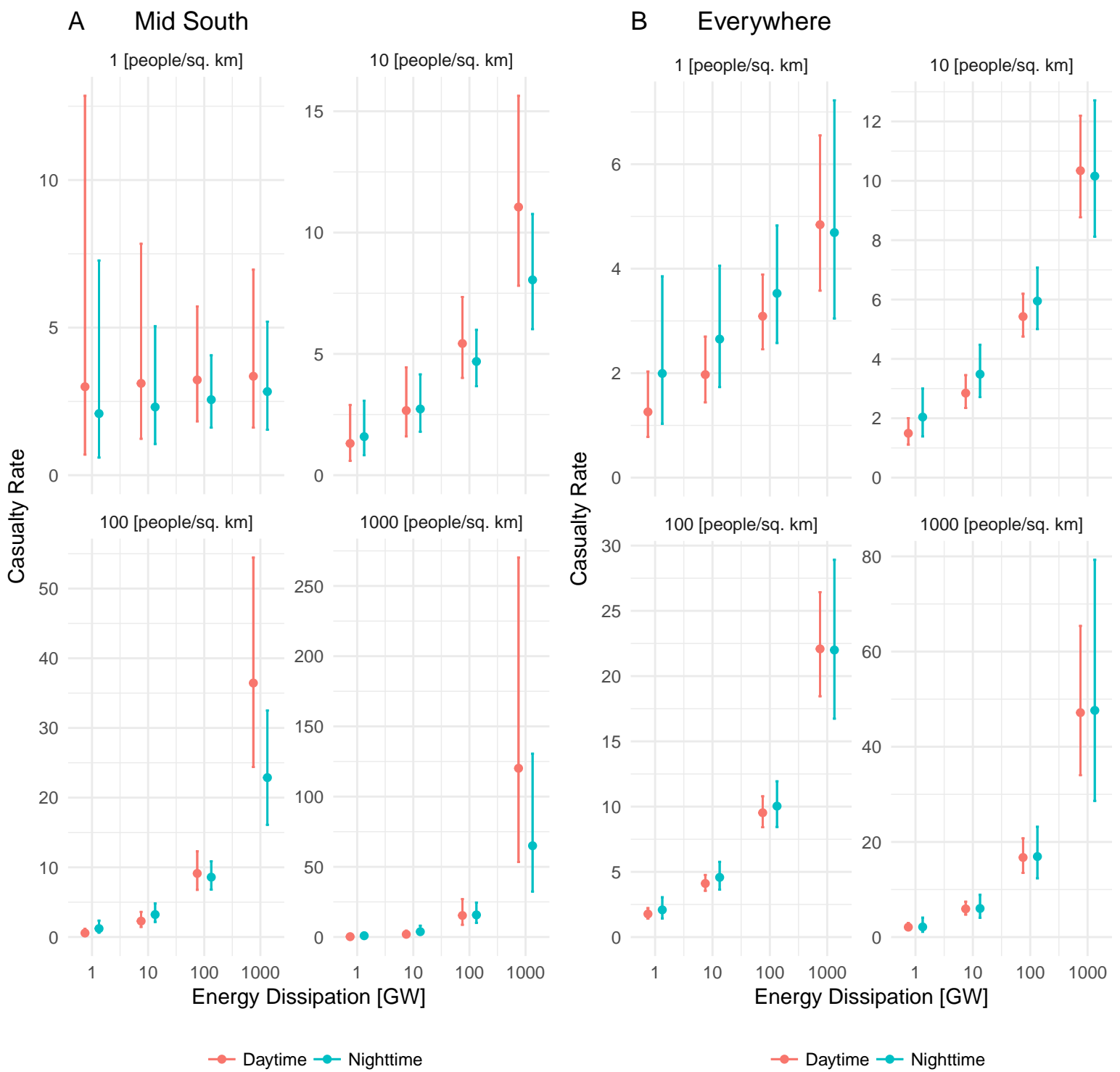
FIG. 9. Predicted casualty rates on week days and on weekends for the greater Mid South (A) and elsewhere

(B). The vertical lines indicate the $95 \%$ uncertainty bounds.
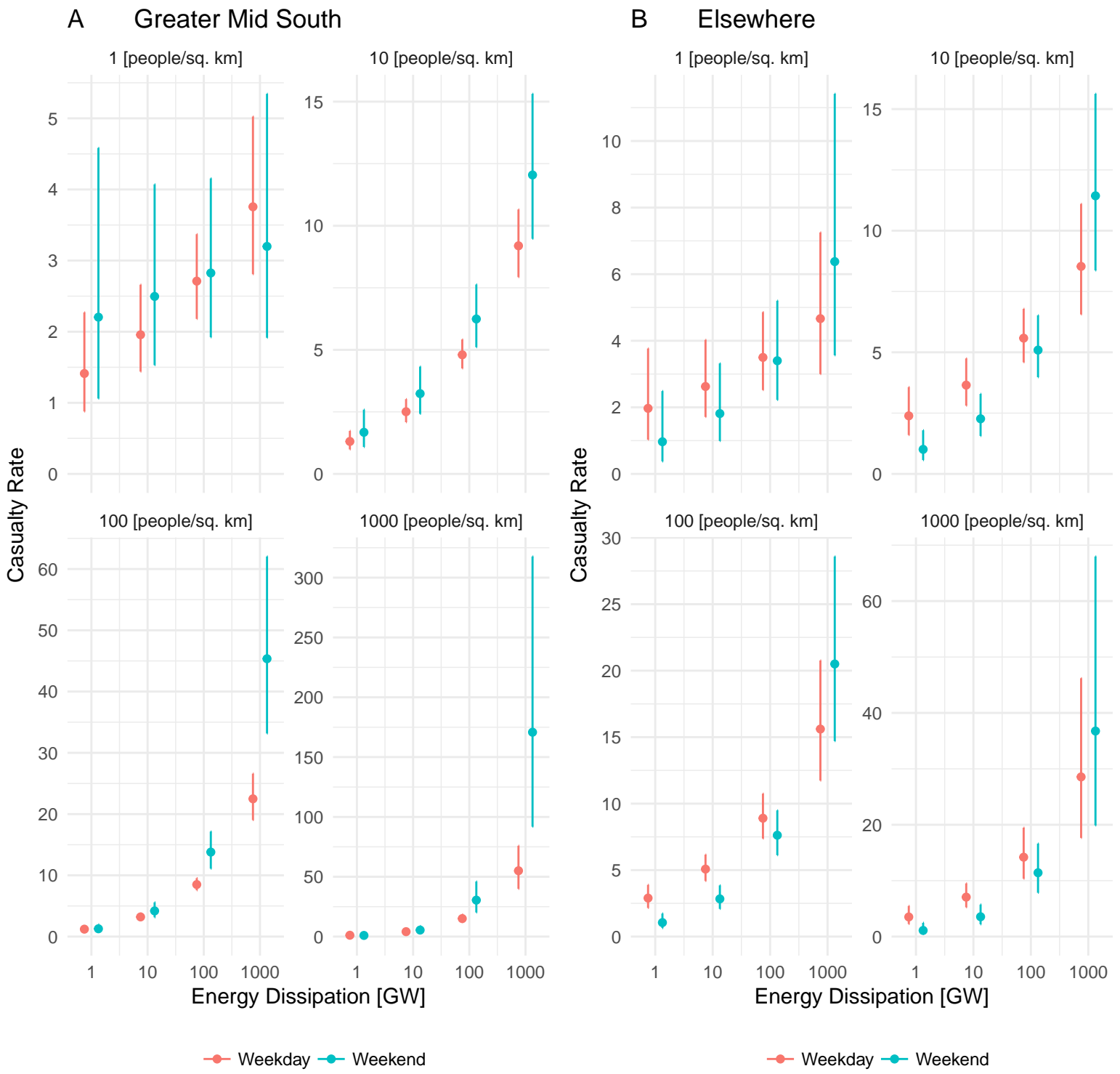

density of 300 people $/ \mathrm{km}^{2}$. The vertical lines indicate the $95 \%$ uncertainty bounds.

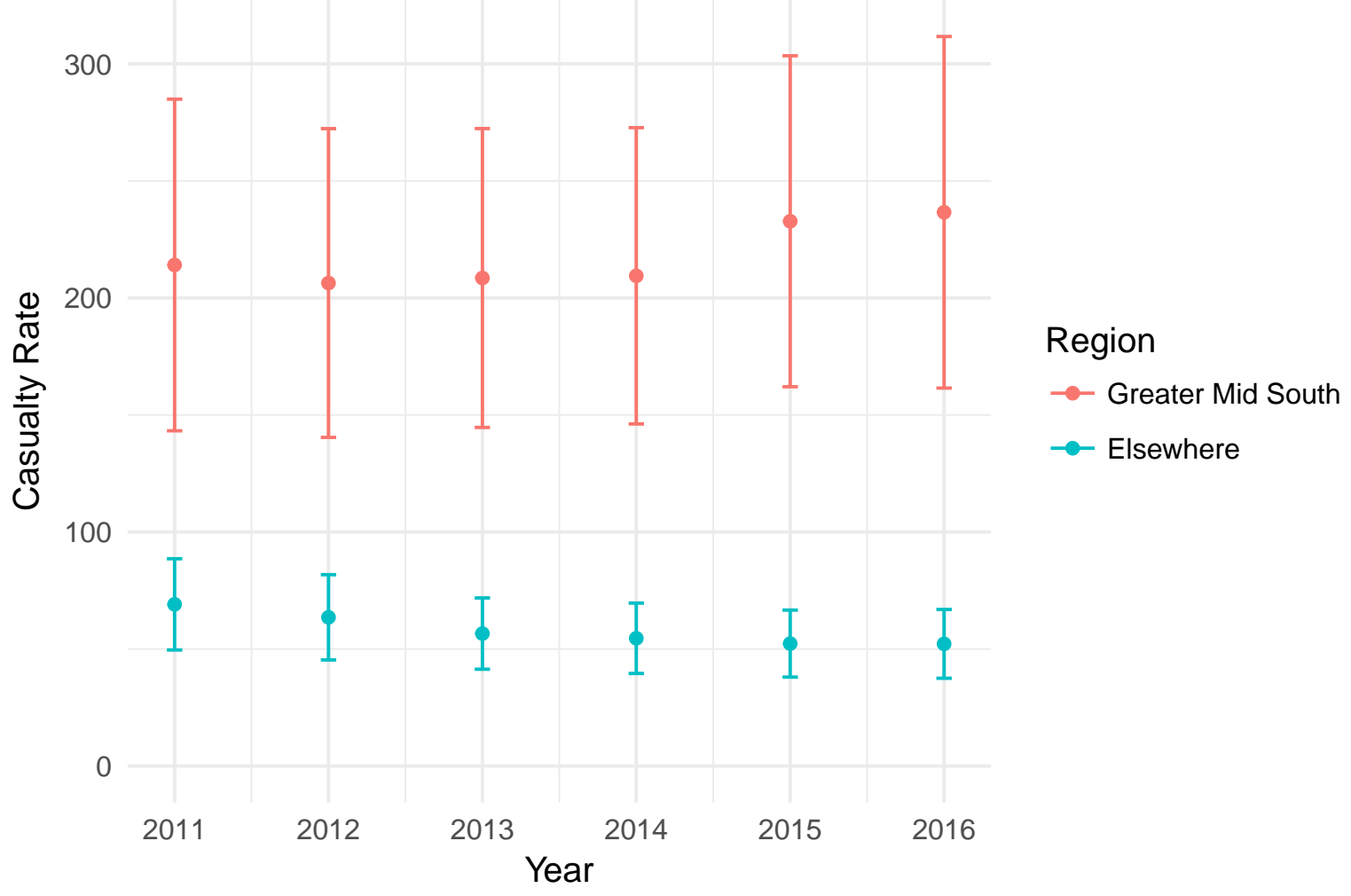

